\title{
24742 - COMPARISON OF ENDOTRACHEAL TUBE AND LMA ON RESPIRATORY MECHANICS DURING THE INDUCTION OF GENERAL ANESTHESIA IN CHILDREN
}

\section{Soochang Son MD, Chungnam National University Hospital, Daejeon, DAEJEON, Korea}

INTRODUCTION: The respiratory mechanics and respiratory parameters during positive pressure ventilation via the laryngeal mask airway are not well known in children(1).We compared the endotracheal tube and LMA on respiratory mechanics during the induction of general anesthesia in children.

METHODS: After IRB approval and written informed consent,We studied sixty ASA physical status \&\#1030; and II healthy children undergoing general anesthesia. Anesthesia was induced with ketamine $1.0 \mathrm{mg} / \mathrm{kg}$ or propofol $2 \mathrm{mg} / \mathrm{kg}$ iv , rocuronium $1.0 \mathrm{mg} / \mathrm{kg}$, and maintained with $50 \%$ nitrous oxide and $2.0 \mathrm{Vol} \%$ sevoflurane. After inserting the laryngeal mask airway, its cuff was inflated using a balloon cuff gauge until the intracuff pressure reached approximately $60 \mathrm{cmH} 2 \mathrm{O}$. Adequacy of ventilation was assessed by observing the end tidal carbon dioxide wave form, chest wall movement, and by stethoscope auscultation. Data were collected with lung mechanics recorders (Ventcheck, Novametrix Medical system, U.S.) at 5 and 10 minutes after intubation or LMA insertion. The data included Peak Inspiratory Pressure(PIP), Mean airway Pressura(MAP), Peak Expiratory Pressure(PEEP), Inspired Tidal Volume(VTins), Expired Tidal Volume(VTexp), Airway resistance(Raw), and Compliance(Cdyn). RESULTS: No significant difference was observed between the airway pressures, tidal volumes and gas leak fractions of the ETT and LMA groups. In airway resistance and compliance, significant differences were observed between the two groups at 5 and 10 minutes.

DISCUSSION: We concluded that the laryngeal mask airway is superior to endotracheal intubation in terms of airway resistance and compliance in children. The laryngeal mask airway offer an alternative for the children needing to avoid intubation under general anesthesia.

REFERENCES:1. Anesth Analg 1996 82:33-8. 